\title{
Disinventing and Reconstituting Languages
}

Alastair Pennycook and Sinfree Makoni, Eds. Clevedon, UK: Multilingual Matters. 2006. Pp. v +249 .

Those familiar with Pennycook's previous works such as English and the Discourses of Colonialism (1998) or Critical Applied Linguistics: A Critical Introduction (2001) will not be surprised to learn that this latest volume, co-edited with Makoni and titled Disinventing and Reconstituting Languages, challenges many orthodoxies related to the role of English in the world and the nature of language. As far back as his 1994 book, The Cultural Politics of English as an International Language, Pennycook has been contesting the view that the global spread of English has been a natural, neutral, and beneficial process and has argued against fixation on language as an a priori ontological system in favor of focus on "language use as a social, cultural, and political act" (Pennycook, 1994, p. 29). It is not difficult to imagine that the editors' collaboration on this volume was inspired in part by a critique Makoni offered of Pennycook's Critical Applied Linguistics suggesting that in the absence of concrete strategies for engaging and collaborating with local communities, "Critical Applied Linguistics runs the danger of being hegemonic to the very communities it seeks to serve" (Makoni, 2003, p. 135). Disinventing and Reconstituting Languages is also a natural extension of Makoni's plenary contribution at the 2004 American Association of Applied Linguistics conference in Portland where he proposed a vision of applied linguistics grounded less in an Anglo-American or Western world view, but having greater relevance to a variety of sociolinguistic contexts (Makoni, 2005). Following a forward by Ofelia García, the book is divided into 10 chapters covering the following three areas: the socio-political contexts from which current understandings of language have grown, the way current conceptions of language have limited development of a more nuanced understanding of how people communicate, and the pedagogical implications a language disinvention and reconstitution process might have.

Pennycook and Makoni use much of chapter 1 to catalogue instances of language invention at the hands of linguists, politicians, and lexicographers. The authors foreground their position that the initial naming and classifying of languages was a performative act, a process of invention that "called the languages into being" (p. 10). Pennycook and Makoni argue that the same process served to reduce, codify, and constrict language while simultaneously relegating creoles and mixed language practices to the sphere of illegitimacy. Following a discussion of the analytical quandaries involved in cataloguing languages and defining language boundaries, Pennycook and Makoni turn to what becomes a central theme throughout the book: the notion that despite a belief that languages are inventions, "the effects of language inventions are very real" (p. 21).

Chapter 2 by Heryanto draws a parallel between the reinvention of vernacular bahasa into the language of Bahasa Indonesia and the founding of Indonesia as a nation, processes Heryanto argues were complementary in execution and design. Heryanto notes that pre-colonial spoken bahasa transcended European notions of "language" and "culture" and constituted a form of social activity that encapsulated local religion, culture, cosmology, manners, norms, and interlocutors' social standing. As Heryanto points out, while the local population gained a language and literacy, they also began a process of severing ties with a previous social order and way of perceiving and interacting with the world. Heryanto's contribution provides a fitting 
introduction to what becomes a secondary theme in the volume, that of the damage wrought upon communities compelled to reimagine local vernaculars through a Western framework.

In chapter 3, Makoni and Mashiri examine flaws in previous attempts to conceptualize African languages, arguing that the conclusions reached by linguists and anthropologists regarding the number and nature of African languages, as well as the boundaries between them, have rarely been accurate reflections of local speech communities (see also Makoni, 2003; Zeleza, 2006). The authors argue that defining, codifying, and repackaging local languages through dictionaries and other means resulted in indigenous languages being "bent to embody European meanings" (p. 78), and established distinctions between languages and speakers that became self-perpetuating and were often exploited for nationalist ends. Makoni and Mashiri propose a shift away from the state-centric language policies of the past and point to new urban vernaculars, replete with "linguistic amalgams and transidiomatic expressions" (p. 85), which they feel need to be acknowledged not as linguistic aberrations but as the verbal repertoires already in use as people engage in a multitude of cultural and linguistic affiliations.

In chapter 4, Pennycook further deconstructs the notion that the English language exists beyond the metalanguage and discourses that have been invented to discuss it. Pennycook argues that the process of invention has served to depoliticize the way people think of English and has allowed many to cling to a belief that English as an International Language (EIL) is a neutral, value-free instrument, far removed from the language's initial imperialist spread across the globe. Furthermore, Pennycook contends that rather than fulfilling oft-cited promises to level the global economic playing field or raise societies in developing countries out of poverty, the spread of English has aided processes of globalization, entrenched social and class distinctions, and restricted the options available to people who do not speak the language. In Pennycook's estimation, "English is not so much a language as it is a discursive field: English is neoliberalism, English is globalization, English is human capital” (p. 112).

The next section of the book begins with Branson and Miller's study of sign languages in Bali. The authors describe the failure of hearing linguists to subordinate signing to spoken linguistic molds and the limits of conventional analysis to acknowledge language features that lay beyond predefined boundaries. In likening the signing communities they study in north Bali to a fragile ecology, the authors quote Mülhäusler (1996), who proposed a reorientation from "linguists being players of academic language games to becoming shop stewards for linguistic diversity, and to addressing moral economic and other 'non-linguistic' issues"(p. 130) as well.

Chapter 6 documents the marginalization of indigenous languages during different periods in Brazil's history. In expanding upon themes he explored in a 2005 TESOL Quarterly article, Menzes De Sousa asserts that the denial of coevalness employed by Western missionaries, linguists, and policy makers helped ensure that indigenous languages and ways of knowing would never be afforded status equal to that of their Western counterparts. The author notes that even later efforts purportedly designed to preserve and validate indigenous languages through the creation of grammars and descriptions contributed to the languages' elimination in their original forms. What is more, attempts for students to acquire literacy in their mother tongues were often instigated as part of a cynical policy of transitional bilingualism designed to prepare students for the study of the national language, Portuguese. In an irony that is mirrored 
elsewhere in the book, Menzes De Sousa details how the dominant culture ultimately entrusts itself to define and preserve a minority culture that it does not understand, and how linguists and anthropologists teach minority children to write indigenous languages that the instructors themselves routinely fail to fully comprehend.

Presented as a third generation view of Vygotskian psycholinguistics, Thorne and Lantolf's Linguistics of Communicative Activity (LCA) seeks to reorient language not as an abstract object but as a living cultural communicative process. In chapter 7 , the authors argue that the effort to establish linguistics as a legitimate science has severely marginalized the human and social aspects of communicative activity that imbue language with meaning. Seen in this light, grammar is emergent and constantly developing in everyday human relations rather than a fixed, a priori code. In fact, Thorne and Lantolf contend that as corpus linguistics expands, it will become clear that few grammatical rules "hold up without recourse to hedge-categories such as exceptions, aberrations and special cases" (p. 184).

This section of the book ends with Richardson's exploration of hip-hop discourse in African American Vernacular English (AAVE) and African American English. Richardson works from the perspective of language as a form of resistance to dominant social power relations and as a site of identity negotiation. Specifically, Richardson discusses the multiple and even contradictory meanings words can assume in hip-hop rhymes and how this potential for expanded meaning-making provides fertile ground for critiquing popular social stereotypes.

The final section of the book considers the pedagogical implications a language disinvention and reconstitution process might have. In chapter 9, Busch and Schick examine the role of the nation state in language policy during the disintegration of the former Yugoslavia. Rather than reflecting the heteroglossia and cultural diversity that existed, the redrawing of national, ethnic, and linguistic borders mirrored the rise in ethno-national aspirations and linked notions of "pure language", national unity, and the "motherland." Busch and Schick detail how, at the school level, in Bosnia-Herzegovina this resulted in new curriculums, materials, and policies designed to delineate three separate cultures, languages, and histories. In this postconflict context, where education remains overwhelmingly informed by a separatist and nationalist agenda, the authors' part in helping to develop the interdisciplinary school textbook Pogledi (Views) becomes all the more noteworthy. In proposing heteroglossia as a starting point and through the incorporation of a diversity of authentic texts and individual voices, Pogledi runs counter to the dominant nationalist agendas by allowing "pupils and teachers to recognize themselves and their linguistic practices... and relieves them from the pressure of a single prescribed standard" (p. 217).

In the final chapter of the book, Canagarajah suggests much can be gleaned from premodern communities when considering the hybrid and fluid nature of language in many present-day cosmopolitan centers and diaspora communities. As Canagarajah notes, in many precolonial settings, the lines separating different language groups were blurred and the notion of community was more a spatial than linguistic or cultural concern. Canagarajah argues it can no longer be assumed that the vast majority of people subscribe to a single language code or claim membership in a single community. Given the dynamic pluralism and diversity of the communal affiliations Canagarajah describes, I could not help but recall what Makoni and Meinhoff (2003) 
elsewhere referred to as communitarian languages in Africa, "languages' as defined by users across a variety of conventional boundaries" (p. 7), and the notion of stylistic inventories that enable people to communicate and interact despite an absence of shared mother tongues and linguistic rules. Canagarajah suggests that to help students shuttle between the myriad communities around them, a shift on several fronts is required, from assumptions of commonality to assumptions of language difference, from an obsession with correctness to a concern for developing communication strategies and a repertoire of codes, and from a focus on grammatical rules and target language to the promotion of greater metalinguistic awareness and a more intuitive understanding of how languages work.

Each chapter of Disinventing and Reconstituting Languages effectively documents the multiple imbrications of language, society, culture, and politics. The variety of local contexts addressed provides ample evidence to counter assumptions of a global monolingual norm or the existence of languages as a priori or politically neutral systems. If nothing else, the book powerfully juxtaposes the purported neutrality and scientific objectivity of conventional Saussurean linguistics with images of a modernist Western discipline that continues to perceive and catalogue communication in other cultures through a subjective and value-laden prism.

Despite the authors' advocacy for a more thoughtful and less hegemonic approach to engagement with local communities, one could nonetheless be forgiven for wondering what specific pedagogical implications the work might have, or as Canagarajah puts it at the start of chapter 10, "So where do we go from here?" (p. 233). As Makoni has suggested elsewhere regarding the use of local varieties of English, the book counters facile arguments that the promotion of World Englishes will "resolve the moral dilemma through its localization of English" (Makoni \& Meinhof, 2003, p. 9). Clearly Pennycook and Makoni are suggesting a fundamental rethinking of language that goes far beyond the promotion of EIL or an increased awareness of human and linguistic rights in the classroom. In so doing, however, the various contributors open several proverbial cans of worms. For example, can language instruction, intervention, and description ever be truly divorced from the trappings of an artificial process of language invention? From a practical standpoint, what would standards look like were the "radical pluralism" (p. 235) Canagarajah advocates employed, and what implications would it have for language testing? The logical conclusions that one might draw from this volume with regards to education would likely meet with a very mixed reaction from institutions, parents, and policy makers, many of whom would undoubtedly draw the line at tolerating the use of creoles or other seemingly aberrant languages in school settings (consider, e.g., the debate that raged concerning the use of AAVE in American schools during the 1990s). Additionally, those with faith in the materially emancipatory powers of English might be reluctant to teach local Englishes over the seemingly pure British or American varieties. Finally, it is not clear whether a language disinvention and reconstitution process could avoid pitfalls of the sort that hindered even well-intentioned efforts to preserve and protect minority languages.

Admittedly, it is perhaps unreasonable to expect questions of this nature to be answered in a volume of this size and scope. Disinventing and Reconstituting Languages is ultimately about posing questions and instigating further reflection and debate while calling for a more nuanced understanding of language use at local levels. Far from suggesting an alternative framework to replace our current views of language, Pennycook and Makoni propose a shift 
away from a one-size-fits-all approach that seeks to superimpose a universal Western conception of language across a variety of local contexts. As Pennycook (2001) freely admits, his penchant for "problematizing givens" and attempts to make applied linguistics "more politically accountable" (p. 7) has brought him no shortage of detractors. Indeed, those who have criticized his work as nothing more than a simplistic marriage of applied linguistics and critical theory, to say nothing of those who have dubbed Pennycook the enfant terrible of the field (as reported by McCarty, 1996), are unlikely to change their views based on anything found in Disinventing and Reconstituting Languages. Yet to dismiss this work wholesale because it comes under the Critical Applied Linguistics umbrella would be extremely shortsighted. Beyond the numerous salient arguments the various authors raise regarding the nature of language, Disinventing and Reconstituting Languages also invites questions of long-term relevance to applied linguistics as a field. Indeed, whether mainstream linguistics will merely make room for participation from those on the periphery of Western academic circles (provided, of course, that Western academic conventions are adhered to), or embrace a larger scale transformation remains to be seen. Nonetheless, as information from local contexts and epistemologies casts doubt on an increasing number of linguistic "givens" and proffers avenues of future reform and investigation, debate surrounding the evolution of the field will continue to grow. While Pennycook and Makoni are unlikely to win over skeptics of the contribution critical theory can make to our understanding of language and the field of applied linguistics, readers with a questioning nature and an interest in the ramifications of language invention will find Disinventing and Reconstituting Languages to be a book with a great deal to offer.

\section{DARAGH HAYES}

\section{REFERENCES}

Makoni, S. (2003). [Review of the book An introduction to applied linguistics: From practice to theory]. Applied Linguistics, 24, 130-137.

Makoni, S. (2003). [Review of the book Critical applied linguistics]. Applied Linguistics, 24, 130-137.

Makoni, S. (2005). Toward a more inclusive applied linguistics and English language teaching: A symposium. TESOL Quarterly, 39, 716-719.

Makoni, S., \& Meinhof, U. H. (Eds.). (2003). Africa and applied linguistics [Special Issue]. AILA Review, 16.

McCarty, S. (1996). East meets West and South in Hong Kong [Electronic version]. Asia-Pacific Exchange (Electronic) Journal, 3(1). Retrieved February 25, 2007, from http://www.waoe.org/steve/hongkong.html.

Menzes De Souza, L. M. (2005). A change of skin: The grammar of indigenous communities in Brasil. TESOL Quarterly, 39, 724-728.

Pennycook, A. (1994). The cultural politics of English as an international language. Harlow, UK: Longman.

Pennycook, A. (1999). Introduction: Critical approaches to TESOL. TESOL Quarterly, 33, 329348.

Zeleza, P. T. (2006). The inventions of African identities and languages: The discursive and developmental implications [Electronic version]. Selected proceedings of the $36^{\text {th }}$ annual 
Teachers College, Columbia University, Working Papers in TESOL \& Applied Linguistics, 2007, Vol. 7, No.1 Book Review

conference on African linguistics. Retrieved February 25, 2007, from http://www.lingref.com/cpp/acal/36/abstract1402.html. 